\title{
Predictors of femoral shortening for pediatric developmental hip dysplasia surgery: an observational study in 435 patients
}

Nabil Alassaf

\begin{abstract}
Background: Open reduction of the congenitally dislocated hip may not be possible without femoral shortening. The goal of this study is to develop a prognostic prediction model for the need of femoral shortening in children undergoing anterior open reduction for the treatment of developmental dysplasia of the hip (DDH). The secondary objective was to determine if femoral shortening influences the risk of adverse events.

Methods: A cohort from February 1, 2008 thru July 31, 2017 was studied retrospectively at a single centre. Patients between the age of 1 and 8 years, having international hip dysplasia institute (IHDI) grade 3 and 4, undergoing primary anterior open reduction for DDH were included in the study. The outcome of interest was femoral shortening, and the potential predictors were age, sex, side, body mass index and IHDI grade. Logistic regression was employed to identify the independent predictors and was followed by internal validation using bootstrapping. In addition, complications encountered were recorded and analysed.

Results: A total of 548 hips in 435 patients were included. Median follow-up (interquartile range) was 27 (13-48.25) months. Femoral shortening was needed on 119 hips. Factors that increased the probability of femoral shortening in the reduced model were age, male gender, and IHDI grade 4. Adjusting for IHDI and the addition of pelvic osteotomy, the probability of recurrence was lower when femoral shortening is included and higher with increased patient age. There were more deep infections when femoral shortening is added. Femoral shortening did not affect the occurrence of avascular necrosis.

Conclusion: In addition to age and superior displacement of the femoral head, male gender is considered to be an independent predictor for needing femoral shortening. Studying the probability of femoral shortening in DDH surgery may optimize family education, operating room preparation, and operative time utilization. Moreover, there appears to be less risk of recurrence when femoral shortening is performed at the cost of higher probability of deep surgical site infection.
\end{abstract}

Keywords: Hip dislocation, Complications, Child, Osteotomy

(C) The Author(s). 2018 Open Access This article is distributed under the terms of the Creative Commons Attribution 4.0 International License (http://creativecommons.org/licenses/by/4.0/), which permits unrestricted use, distribution, and reproduction in any medium, provided you give appropriate credit to the original author(s) and the source, provide a link to the Creative Commons license, and indicate if changes were made. The Creative Commons Public Domain Dedication waiver (http://creativecommons.org/publicdomain/zero/1.0/) applies to the data made available in this article, unless otherwise stated. 


\section{Background}

Femoral shortening is a fundamental component of the surgical treatment of developmental dysplasia of the hip (DDH) and usually considered on an individualized basis. Surgeons use femoral shortening to make open reduction possible when the soft tissues are significantly contracted and also occasionally added to alleviate pressure on the reducible femoral head. Excessive tension across a reduced hip may increase the risk of avascular necrosis, redislocation and probably stiffness [1-3]. With few exceptions, femoral shortening is most widely accomplished through an additional lateral surgical exposure [4]. Ombredane was the first to described subtrochanteric femoral shortening in combination with the open reduction to treat congenital hip dislocation in children [5]. In the past, femoral shortening was considered only for patients who did not respond to prolonged preoperative traction [6]. An alternative to skeletal traction is an external distractor, which Wojciechowski et al. used to lower the femoral head before open reduction and acetabuloplasty [7]. This method, however, entails two-stage surgery and carries the additional risk of pin site infection. Earlier, Grill used this technique to avoid femoral shortening in children who were older than 6 years of age [8]. In an analysis of 39 hips, Schoenecker et al. did not find an advantage for preoperative traction in patients older than 3 years of age, particularly, for the reduction of avascular necrosis rate [1].

Subtrochanteric rather than intertrochanteric osteotomy, is commonly used in femoral shortening. Ashley et al. suggested that the amount of shortening required is the overlap between the femoral shaft and the proximal fragment, which usually measures 2 to $3 \mathrm{~cm}$ [9]. They fixed the two pieces using a four-hole plate without changing the rotation. Shih et al., in a study of 20 hips in children between the age of 2 and 11, had no shortening that exceeded $2 \mathrm{~cm}$ [10]; there were one redislocation and one resubluxation, both believed to be secondary to the overcorrection of femoral head anteversion. Galpin et al. reviewed 33 hips in children over the age of 2 who had open reduction and femoral shortening; there was no symptomatic leg length discrepancy [11]. As we are beginning to understand the pathoanatomy of DDH further, there are fewer varus producing proximal femoral osteotomies performed today as persistent femoral neck varus may result [2]. Rotating osteotomies to improve anteversion, which is occasionally severe in DDH patients, continue to be only cautiously used. Sankar et al. further studied the effect of age and femoral head migration on the overall rate of femoral shortening [12].

When deemed useful, femoral shortening require extra operative time and equipment, and it may also increase the need for the administration of blood products. Being informed about the probability of femoral shortening beforehand will help enlighten the patient's family as well as the healthcare providers about this surgical step. The goal of this study, therefore, is to develop a prognostic prediction model for the need of femoral shortening in children who are undergoing anterior open reduction for the treatment of $\mathrm{DDH}$. The secondary objective is to examine whether or not femoral shortening alters the risk of adverse events.

\section{Methods \\ Patients}

This observational study was approved by an institutional review board, and conducted in compliance with the Declaration of Helsinki. A prognostic model development, retrospective cohort study design. A database in a single tertiary care facility was queried for consecutive patients between the first of February 2008 and the end of July 2017. Eligibility criteria were primary surgery for DDH, ages between 1 and 8 years at the time of operation, undergoing open reduction through an anterior approach, and international hip dysplasia institute (IHDI) grades 3 and 4. Exclusion criteria were non-idiopathic hip dislocation secondary to local or systemic diseases, reoperation, patients less than 1 years or older than 8 , as these patients are typically treated with a different surgical protocol. Open reductions through medial approach and IHDI grade two or less were factors that were not analyzed.

\section{Surgical procedure}

The decision to proceed with femoral shortening was based on intraoperative assessment without a cut-off age, namely, either the inability to reduce the hip or the hip being reducible, but under excessive tension. After anterior exposure and capsulotomy of the hip, femoral shortening was performed through a separate incision, using a standard lateral approach to the femur. Adductor longus, rectus, and iliopsoas tenotomies were performed routinely. The amount of shortening varied among the patients. Two transverse subtrochanteric osteotomies are done, and a 4-holes plate is used in addition to immobilization with a hip spica. External rotation of the distal fragment was not done in all patients and instead reserved for hips with marked anteversion compromising stability. A pelvic osteotomy is then added after femoral shortening, followed by capsular repair. If the dislocation is bilateral, the other hip is scheduled on a different day. No preoperative traction was used.

\section{Outcome and predictors}

The addition of femoral shortening during open reduction in primary pediatric DDH surgery was the dichotomous outcome of interest. The medical records and radiographs were examined for demographic parameters and surgical details. The following potential preoperative predictors were extracted and included in the analysis: 
Age in months, sex, side of the operated hip, Body mass index (BMI), and severity of hip displacement as outlined using the IHDI classification. Data pertaining to complications were collected and compared between hips that had femoral shortening and those who did not. The risk of recurrence and avascular necrosis were analysed while controlling for the following parameters: femoral shortening, age, pelvic osteotomy, and IHDI grade. Recurrence was defined by persistent disruption of the Shenton-Menard line and avascular necrosis was determined based on Salter's criteria [13].

\section{Data analysis}

The full model included five predictors. A sample that included more than 50 events of femoral shortening was felt to be adequate according to the rough 1:10 rule [14]. Five multiple imputations were performed for missing values at random. For univariable analysis, the normality of distribution and homogeneity of variances for the continuous variables were determined graphically. Mann-Whitney-Wilcoxon test was used in the absence of normality, and an independent Student's t-test was used for the parametric values. Chi-square test and Fisher's exact test were used for count data. In the multivariable analysis, the predictors' selection was done by backwards eliminating binary logistic regression using $p$-value. The stopping rule was the Akaike information criterion (AIC). Fractional polynomials were used to handle continuous variables during model selection. For internal validation, model discrimination was computed using 100 samples, the area under the curve (AUC) was calculated and the receiver operator characteristic (ROC) curve was plotted. The variance inflation factor (VIF) was obtained for each predictor to check for multicollinearity with a value of 10 or more set as high. To correct for optimism, the shrinkage factor was calculated through 200 bootstraps. After shrinkage, the calibration slope was calculated and illustrated using 40 repetitions. A $p$-value of less than 0.05 was considered significant in the univariable comparisons. $\mathrm{R}$ software was used for the statistical calculations, Version 3.4.3 (R Foundation for Statistical Computing, Vienna, Austria).

\section{Results}

In total, 548 hips in 435 patients were eligible for inclusion. Forty-four hips (8\%) had missing height value and were replaced using multiple imputation. Importantly, 13 hips in 8 patients were excluded because they were IHDI grade 2, and none required femoral shortening. A comparison of the femoral shortening group and the control group is presented in Table 1. Side was the only factor that did not show statistical significance in the unadjusted association. Most of the femoral shortening group, 116 hips (97\%), Which had a higher median age, underwent pelvic osteotomy after performing femoral shortening compared to 400 hips $(93 \%)$ in the second group ( $p=0.119)$.

After logistic regression, starting with the full model and eliminating backwards, age, male gender, and IHDI grade were retained in the final model (Table 2). The regression coefficients were multiplied by the shrinkage factor of 0.97 . The probability of femoral shortening can be calculated by routinely available predictors using the following formula: $1 /(1+$ exponential $(-(-7.11+$ age in months * $0.10+$ Male gender * $0.62+$ IHDI grade $4 * 2.64))$ ), where 1 in the equation is used for males and IHDI grade 4, 0 is inserted for Females and IHDI grade 3. For example, a 17-month old girl with IHDI grade 3 dislocation would have only a $0.4 \%$ probability of needing femoral shortening. In contrast, a 77-month old boy and IHDI grade 4 has a probability of femoral shortening as high as $98 \%$.

The VIF was low for all predictors, which indicates minimal multicollinearity (Table 2). The performance measure, calibration that illustrates the distribution of the predicted probabilities of hips with and without femoral shortening is presented in Fig. 1. The line is close to the 45 degrees perfect straight line with a slight underestimation in the middle range and mild overestimation in the higher range. Discrimination, which is the model's ability to differentiate between hips that do or do not experience femoral shortening, is shown as an ROC curve in Fig. 2. AUC was 0.89, which reflects a strong discriminative ability of the model.

The documented complications are listed in Table 3. Except for deep infection, there was no difference in the crude comparison. However, multivariable analysis revealed that recurrence of instability is associated with

Table 1 Participant characteristics at baseline

\begin{tabular}{|c|c|c|c|c|c|c|}
\hline Characteristic & $\begin{array}{l}\text { All Hips } \\
(n=548)\end{array}$ & $\begin{array}{l}\text { femoral shortening } \\
(n=119)\end{array}$ & No femoral shortening $(n=429)$ & Odds ratio & $95 \% \mathrm{Cl}$ & $P$ Value \\
\hline Median age (IQR), months & $23(19-32)$ & $39(31-52.5)$ & $21(19-26)$ & 1.11 & $1.09-1.14$ & $<0.001$ \\
\hline Female sex, \% & $461(84)$ & $91(76)$ & $370(86)$ & 1.93 & $1.16-3.20$ & 0.015 \\
\hline Left side, \% & $295(54)$ & $67(56)$ & $228(53)$ & 1.14 & $0.75-1.71$ & 0.612 \\
\hline Mean BMI (range) & $15.61(8.41-25.97)$ & $14.89(10.65-25.97)$ & $15.81(8.41-24.85)$ & 0.87 & $0.80-0.94$ & $<0.001$ \\
\hline$|H D| 4, \%$ & $461(84)$ & $118(99)$ & $343(80)$ & 29.59 & $4.08-214.80$ & $<0.001$ \\
\hline
\end{tabular}

IQR interquartile range, $B M I$ body mass index, IHDI international hip dysplasia institute 
Table 2 The model for the probability of femoral shortening in pediatric DDH surgery

\begin{tabular}{lllll}
\hline Predictors & Odds ratio & $95 \% \mathrm{Cl}$ & P Value & VIF \\
\hline Age in months* & 1.11 & $1.08-1.13$ & 0.001 & 1.003 \\
Male gender & 1.89 & $0.10-3.60$ & 0.052 & 1.002 \\
IHDI grade IV vs III & 15.44 & $2.05-116.21$ & 0.008 & 1.000
\end{tabular}

$D D H$ developmental dysplasia of the hip, IHDI international hip dysplasia institute, VIF variance inflation factor, $\left(^{*}\right)$ per unit change

older age (coefficient $=0.003$, standard error $=0.0009$, $p<0.001$ ) and the lack of femoral shortening (coefficient $=-0.07$, standard error $=0.028, p=0.015$ ). Avascular necrosis was not influenced by femoral shortening.

\section{Discussion}

This study established and internally validated the first prediction model for femoral shortening in pediatric DDH surgery. Age, male sex, and IHDI grade 4 were the independent predictors. Both AUC and visual representation of the calibration presented here indicates a useful model [15]. These findings are in agreement with those of Sankar et al., who found in a study of 72 hips that femoral head superior displacement and age older than 3 years are associated with femoral shortening [12].

Age was significantly higher in femoral shortening patients, even after adjustment. Klisic et al. performed femoral shortening routinely after the age of 5 [4]. Dimitrio et al. and Ryan et al. did femoral shortening for all patients older than 3 years $[2,16]$. Femoral shortening was performed routinely by Erturk et al. on 49 hips of children between the ages of 2 and 5, and only one hip

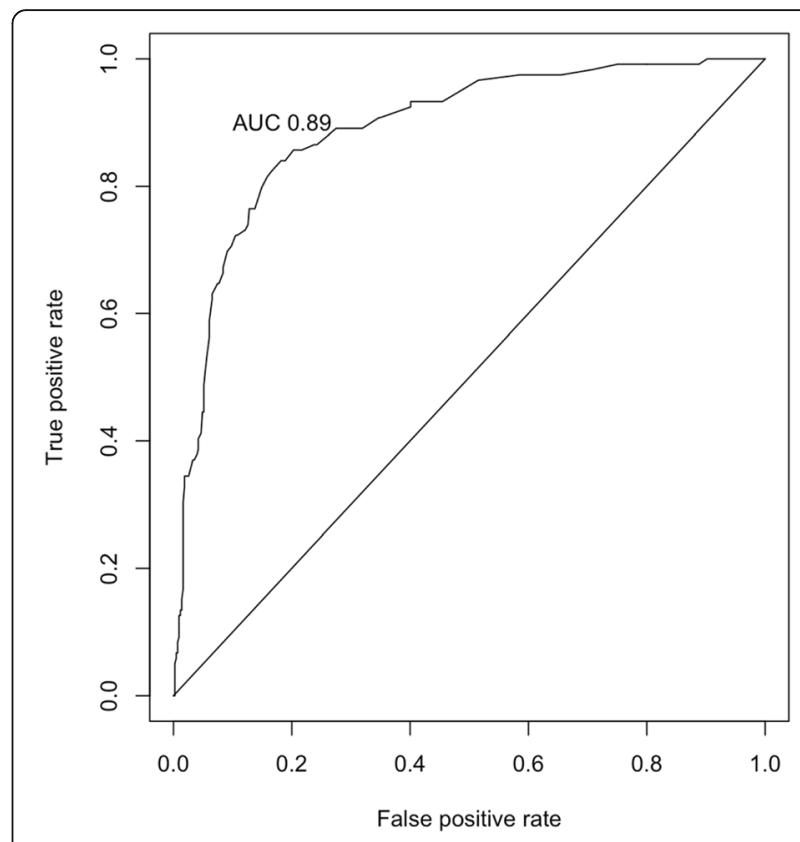

Fig. 2 The receiver operator characteristic (ROC) curve, the area under the curve (AUC) $95 \%$ confidence interval is (0.86 to 0.92)

redislocated [17]. Ning et al. performed femoral shortening in all of the 864 developmentally dysplastic hips in children older than three, $27.4 \%$ of these patients developed AVN of grade II or higher based on the Kalamchi classification, and their redislocation rate was 1.6\% [18]. The side of the operated hip did not affect the rate of femoral shortening.

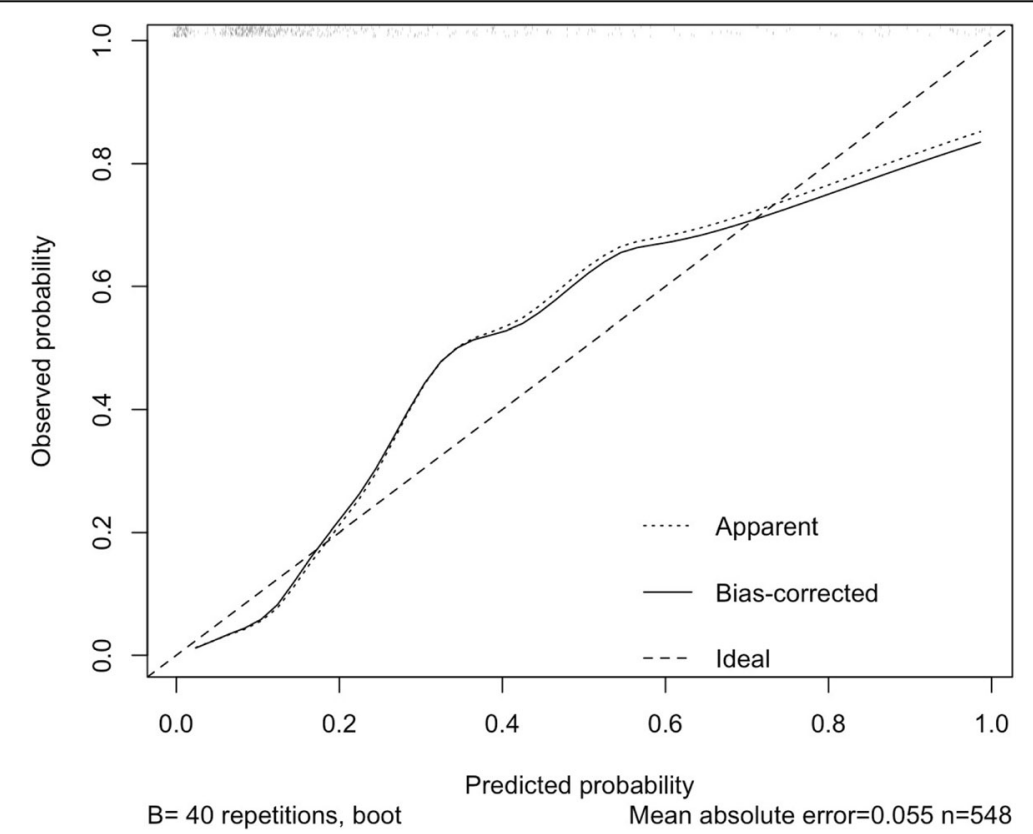

Fig. 1 The calibration plot 
Table 3 Complications

\begin{tabular}{|c|c|c|c|c|c|}
\hline & $\begin{array}{l}\text { All Hips } \\
(n=548)\end{array}$ & $\begin{array}{l}\text { Femoral } \\
\text { shortening } \\
(n=119)\end{array}$ & $\begin{array}{l}\text { No Femoral } \\
\text { shortening } \\
(n=429)\end{array}$ & $P$ Value & Additional surgeries \\
\hline $\begin{array}{l}\text { Median Follow-up } \\
\text { (IQR), months }\end{array}$ & $27(13-48.25)$ & $25(12-40.5)$ & $28(13-54)$ & 0.096 & \\
\hline $\begin{array}{l}\text { Recurrent } \\
\text { displacement, \% }\end{array}$ & $31(5.7)$ & $6(5)$ & $25(5.8)$ & 0.917 & 21 hips underwent revision \\
\hline Avascular necrosis, \% & $30(5.5)$ & $5(4.2)$ & $25(5.8)$ & 0.644 & One patient had greater trochanter transfer \\
\hline $\begin{array}{l}\text { Cast related } \\
\text { fractures, } \%\end{array}$ & $12(2.2)$ & $1(0.8)$ & $11(2.6)$ & 0.477 & $\begin{array}{l}\text { One patient had operative fixation of tibia fracture and one femur fracture } \\
\text { reduced under general anaesthesia }\end{array}$ \\
\hline $\begin{array}{l}\text { Full thickness } \\
\text { pressure ulcers, \% }\end{array}$ & $2(0.4)$ & 0 & $2(0.5)$ & 1 & \\
\hline $\begin{array}{l}\text { Unplanned dirty cast } \\
\text { change, } \%\end{array}$ & $7(1.3)$ & $1(0.8)$ & $6(1.4)$ & 1 & \\
\hline $\begin{array}{l}\text { Deep surgical site } \\
\text { infection, \% }\end{array}$ & $4(0.7)$ & $3(2.5)$ & $1(0.2)$ & 0.034 & 3 were debrided once, one hip required several surgeries \\
\hline $\begin{array}{l}\text { Superficial surgical } \\
\text { site infection, \% }\end{array}$ & $1(0.2)$ & 0 & $1(0.2)$ & 1 & \\
\hline $\begin{array}{l}\text { Other early } \\
\text { postoperative } \\
\text { infections }\end{array}$ & $16(2.9)$ & $4(3.4)$ & $12(2.8)$ & 0.759 & \\
\hline persistent stifness & $6(1.1)$ & $1(0.8)$ & $5(1.2)$ & 1 & $\begin{array}{l}\text { Three hips had manipulation under anaesthesia without substantial } \\
\text { improvement }\end{array}$ \\
\hline $\begin{array}{l}\text { Leg length } \\
\text { discrepancy }(>2 \mathrm{~cm})\end{array}$ & $3(0.5)$ & $1(0.8)$ & $2(0.5)$ & 0.521 & \\
\hline Neurological injury & $2(0.4)$ & 0 & $2(0.5)$ & 1 & $\begin{array}{l}\text { One femoral nerve transection and common peroneal nerve entrapment } \\
\text { recovered after K-wire removal and cast change }\end{array}$ \\
\hline
\end{tabular}

IQR interquartile rang

Male gender was associated with a higher probability of femoral shortening, even when the influence of other variables was statistically controlled. This difference can be explained, at least in part by increased muscle and tendon elasticity in females $[19,20]$. BMI was eliminated from the reduced model in the multivariable analysis, as it was significantly lower in the group that had a higher age. BMI tends to decrease after the age of 1 until the age of 5.5 [21]. Because pelvic osteotomy is done after the completion of femoral shortening, it also was not added to the full model as a potential predictor.

Hefti suggested that femoral shortening should "always" be added to open reduction if the upper ridge of the femoral metaphysis is higher than the triradiate cartilage, which is equivalent to IHDI 4 [22]. In a study done by Cordier et al. 10 out of 118 hips required femoral shortening, and in all of these hips, the ossification centre was above the superolateral margin of the acetabulum (Tonnis grade 4) [23]. In the current study, 1 out of the 87 (1\%) IHDI 3 hips required femoral shortening, and a quarter (118/461) of the IHDI grade 4 hips required femoral shortening to achieve a stable intraoperative reduction. The IHDI classification reliability has been tested, and it was used in this study because it does not depend on the presence of an ossific nucleus, which may not be always present [24].

Interestingly, femoral shortening might be protective against the need for additional procedures when combined with OR here, which is consistent with what was reported by Gholve et al., Based on data from 49 hips and a minimum follow-up of five years [25]. The risk of recurrence is increased with age as described in a recent report [18]. Femoral shortening did not affect the risk of avascular necrosis in the current study. In an analysis of 26 hips that underwent open reduction and acetabuloplasty, Akgul et al. performed femoral shortening in 13 hips. Avascular necrosis occurred in 6 hips and was distributed evenly between the two groups [26]. The probability of deep surgical site infection was higher when femoral shortening is performed (Table 3), which is a biologically plausible finding.

The lack of external validation was a limitation in this study. The indication for femoral shortening is clear when the hip fails to reduce after open reduction but deciding to perform femoral shortening based on tight reduction alone is not standardized, and tension on the femoral head is influenced by the extremity position. Although femoral shortening was decided based on 
intraoperative assessment in here, surgeons may add femoral shortening based on preconceived ideas.

\section{Conclusion}

In addition to age and superior displacement of the femoral head, male gender is an independent risk factor for needing femoral shortening. The developed model may thus prove helpful in the preoperative phase. Personalizing the probability of femoral shortening may also further optimize family education, operating room preparation and operative time utilization. Femoral shortening may reduce recurrence in selected patients at the expense of a higher chance of deep surgical site infection.

\section{Abbreviations}

AIC: Akaike information criterion; AUC: Area under the curve; BMI: Body mass index; DDH: Developmental dysplasia of the hip; IHDI: International hip dysplasia institute; IQR: Interquartile range; ROC: Receiver operator characteristic; VIF: Variance inflation factor

\section{Acknowledgements}

The author thanks Hans Reitsma and Omar Kasule for helpful comments on the design of this study.

\section{Funding}

This research received no specific grant from any funding agency in the public, commercial, or not-for-profit sectors.

\section{Availability of data and materials}

The datasets used and/or analysed during the current study are available from the corresponding author on reasonable request.

\section{Authors' contributions}

NA performed data collection, statistical analysis, and wrote the manuscript. The author read and approved the final manuscript.

\section{Ethics approval and consent to participate}

Ethical approval for this study was obtained from King Fahad Medical City, Institutional Review Board (log number 18-187).

\section{Consent for publication}

Not applicable.

\section{Competing interests}

The author declares that he has no competing interests.

\section{Publisher's Note}

Springer Nature remains neutral with regard to jurisdictional claims in published maps and institutional affiliations.

Received: 2 July 2018 Accepted: 12 October 2018

Published online: 19 October 2018

\section{References}

1. Schoenecker PL, Strecker WB. Congenital dislocation of the hip in children. Comparison of the effects of femoral shortening and of skeletal traction in treatment. J Bone Joint Surg Am. 1984;66:21-7.

2. Dimitriou JK, Cavadias AX. One-stage surgical procedure for congenital dislocation of the hip in older children. Long-term results. Clin Orthop Relat Res. 1989:246:30-8.

3. Tönnis D. Surgical treatment of congenital dislocation of the hip. Clin Orthop Relat Res. 1990;258:33-40

4. Klisic P, Jankovic L. Combined procedure of open reduction and shortening of the femur in treatment of congenital dislocation of the hips in older children. Clin Orthop Relat Res. 1976;119:60-9.

5. Ombrédanne DL. Précis clinique et opératoire de chirurgie infantile. Paris: Masson; 1944
6. Herold HZ, Daniel D. Reduction of neglected congenital dislocation of the hip in children over the age of six years. J Bone Joint Surg Br. 1979;61:1-6.

7. Wojciechowski P, Kusz DJ, Cieliński ŁS, Dudko S, Bereza PL. Neglected, developmental hip dislocation treated with external iliofemoral distraction, open reduction, and pelvic osteotomy. J Pediatr Orthop B. 2012;21:209-14.

8. Grill F. Treatment of hip dislocation after walking age. Arch Orth Traum Surg Springer-Verlag. 1984;102:148-53.

9. Ashley RK, Larsen LJ, James PM. Reduction of dislocation of the hip in older children: a preliminary report. J Bone Joint Surg Am. 1972;54:545-50.

10. Shih $\mathrm{CH}$, Shih HN. One-stage combined operation of congenital dislocation of the hips in older children. J Pediatr Orthop. 1988;8:535-9.

11. Galpin RD, Roach JW, Wenger DR, Herring JA, Birch JG. One-stage treatment of congenital dislocation of the hip in older children, including femoral shortening. J Bone Joint Surg Am. 1989;71:734-41.

12. Sankar WN, Tang EY, Moseley CF. Predictors of the need for femoral shortening osteotomy during open treatment of developmental dislocation of the hip. J Pediatr Orthop. 2009;29(8):868-71.

13. Tsukagoshi Y, Kamegaya M, Kamada H, Saisu T, Morita M, Kakizaki J, et al. The correlation between Salter's criteria for avascular necrosis of the femoral head and Kalamchi's prognostic classification following the treatment of developmental dysplasia of the hip. Bone Joint J. 2017;99-B:1115-20.

14. van Smeden M, de Groot JAH, Moons KGM, Collins GS, Altman DG Eijkemans MJC, et al. No rationale for 1 variable per 10 events criterion for binary logistic regression analysis. BMC Med Res Methodol BioMed Central. 2016;16(1):163.

15. Alba AC, Agoritsas T, Walsh M, Hanna S, lorio A, Devereaux PJ, et al. Discrimination and calibration of clinical prediction models. JAMA. 2017; 318(14):1377-8.

16. Ryan MG, Johnson LO, Quanbeck DS, Minkowitz B. One-stage treatment of congenital dislocation of the hip in children three to ten years old. Functional and radiographic results*. J Bone Joint Surg. 1998;80(3):336-44.

17. Ertürk C, Altay MA, Yarimpapuç R, Koruk I, Işikan UE. One-stage treatment of developmental dysplasia of the hip in untreated children from two to five years old. A comparative study. Acta Orthop Belg. 2011;77(4):464-71.

18. Ning B, Yuan Y, Yao J, Zhang S, Sun J. Analyses of outcomes of one-stage operation for treatment of late-diagnosed developmental dislocation of the hip: 864 hips followed for 3.2 to 8.9 years. BMC Musculoskelet Disord 2014 15:1. BioMed Central; 2014;15:401.

19. Winter EM, Brookes FBC. Electromechanical response times and muscle elasticity in men and women. Eur J Appl Physiol. 4 ed. Springer-Verlag; 1991;63:124-8.

20. Kubo K, Kanehisa H, Fukunaga T. Gender differences in the viscoelastic properties of tendon structures. Eur J Appl Physiol. 2003;88:520-6.

21. Cole TJ, Bellizzi MC, Flegal KM, Dietz WH. Establishing a standard definition for child overweight and obesity worldwide: international survey. BMJ. 2000; 320:1240-3

22. Hefti F. Offene Repositionsverfahren. Orthopade Springer-Verlag. 1997;26: $67-74$.

23. Cordier W, Tönnis D, Kalchschmidt K, Storch KJ, Katthagen BD. Long-term results after open reduction of developmental hip dislocation by an anterior approach lateral and medial of the iliopsoas muscle. J Pediatr Orthop B. 2005;14:79-87.

24. Narayanan U, Mulpuri K, Sankar WN, Clarke NMP, Hosalkar H, Price CT, et al. Reliability of a new radiographic classification for developmental dysplasia of the hip. J Pediatr Orthop. 2015;35:478-84.

25. Gholve PA, Flynn JM, Garner MR, Millis MB, Kim Y-J. Predictors for secondary procedures in walking DDH. J Pediatr Orthop. 2012;32:282-9.

26. Akgül T, Bora Göksan S, Bilgili F, Valiyev N, Murat HÖ. Radiological results of modified Dega osteotomy in Tönnis grade 3 and 4 developmental dysplasia of the hip. J Pediatr Orthop B. 2014;23:333-8. 